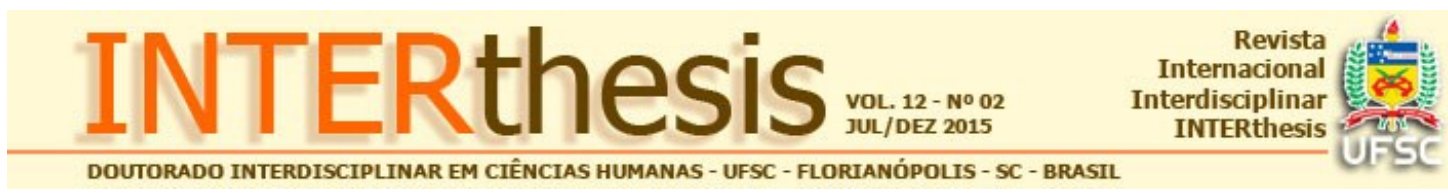

\title{
O LAÇO SOCIAL E O MAL-ESTAR FACE AO DESAMPARO
}

\section{RESUMO}

Cristina Aparecida Tannure Cavalcanti ${ }^{1}$ Maria Cristina Poli ${ }^{2}$

Neste artigo pretendeu-se abordar os discursos como laços sociais, indicados por Lacan, relacionando-os às concepções freudianas do desamparo (Hilflosigkeit) e do mal-estar da civilização. A teoria dos discursos inaugura uma nova forma de pensar as estruturas clínicas e o vínculo social, por articular os campos da linguagem e do gozo, o sujeito e o saber inconsciente. Essa teoria, ao mesmo tempo em que retoma princípios freudianos, avança em impasses deixados pelo mestre vienense, em particular na articulação entre os fundamentos metapsicológicos da constituição subjetiva e as bases conceituais concernentes à cultura e aos laços sociais propriamente ditos.

Palavras-chave: Psicanálise. Laços sociais. Desamparo. Discursos. Mal-estar.

\section{INTRODUÇÃO}

A proposta inicial é percorrer as concepções freudiana e lacaniana à respeito do desamparo como uma figura contemporânea, que permeia constantemente as relações entre os sujeitos, vinculado às mudanças sociais, históricas e políticas da sociedade. Nossa história se faz a partir do outro, através de vários parceiros. Essa dependência que temos do outro, que muitas vezes está fora do vínculo, do laço social, promove uma reativação da oposição coletiva, que é nata, e coloca em foco nosso desamparo, dando origem ao mal-estar. Como comenta Freud no texto de 1930, Mal-Estar na Civilização (ESB, v. XXI, p. 91):

A felicidade [...] constitui um problema da economia da libido do indivíduo. Não existe uma regra de ouro que se aplique a todos: todo homem tem de

\footnotetext{
1 Doutoranda em Psicanálise, Saúde e Sociedade pela Universidade Veiga de Almeida. Secretária executiva na Universidade Federal do Estado do Rio de Janeiro, Rio de Janeiro, RJ, Brasil. E-mail: crisatcpsi@yahoo.com.br

2 Doutora em Psicologia, Université de Paris XIII (Paris-Nord), Pós-Doutorado na Universidade Federal do Rio de Janeiro. Professora do Programa de Pós-Graduação em Teoria Psicanalítica da Universidade Federal do Rio de Janeiro. Coordenadora do Mestrado Interdisciplinar em Psicanálise, Saúde e Sociedade na Universidade Veiga de Almeida, Rio de Janeiro, RJ, Brasil. Pesquisadora do CNPq. E-mail: mccpoli@gmail.com
} 
descobrir por si mesmo de que modo específico ele pode ser salvo (do desamparo). Todos os tipos de diferentes fatores operarão a fim de dirigir sua escolha. É uma questão de quanta satisfação real ele pode esperar obter do mundo externo, de até onde é levado para tornar-se independente dele, e, finalmente, de quanta força sente à sua disposição para alterar o mundo, a fim de adaptá-lo a seus desejos.

O fato de o sujeito ser pulsional, ser animado por algo que não tem objeto nem objetivo definido, o leva muitas vezes ao encontro do desamparo, que é estrutural. Nossa biologia é o nosso desamparo. Atualmente, com o declínio da função paterna, há a perda do lugar simbólico da autoridade. A verticalidade foi sendo modificada para a horizontalidade, comprometendo a figura que norteava a lei social, os limites. As figuras que sustentavam o lugar da autoridade - pai, padre, professor - estão sendo cada vez mais diluídas. Historicamente, a modalidade discursiva produziu um impacto na questão da autoridade, deixando um vazio na tradicional bússola orientadora que a mesma representava.

Neste artigo pretendemos abordar os discursos como laços sociais, elaborados por Lacan (1969-1970), relacionando-os às concepções freudianas do desamparo (Hilflosigkeit) e do mal-estar da civilização. A teoria dos discursos inaugura uma nova forma de considerar a posição do sujeito no vínculo social, articulando os campos da linguagem, do gozo e o saber inconsciente. Essa teoria, ao mesmo tempo em que retoma princípios freudianos, avança em impasses deixados pelo mestre vienense, em particular na articulação entre os fundamentos metapsicológicos da constituição subjetiva e as bases conceituais concernentes à cultura e aos laços sociais propriamente ditos.

Para a psicanálise após Lacan, os discursos como formas de tratamento do mal-estar na cultura são uma noção fundamental. São eles que orientam o sujeito na renúncia e possível recuperação do quantum de gozo que o habitar na cultura lhe exige. A própria psicanálise é considerada neste contexto como um discurso, isto é, como uma modalidade de laço social que opera com o significante e com a perda de gozo, na relação do sujeito com o real.

Como observa Quinet (2009, p. 17) "O mal-estar na civilização é o mal-estar dos laços sociais", que se expressam através dos atos de governar e ser governado, de educar e ser educado, analisar e ser analisado e no ato de fazer desejar e ser desejado. Esses diferentes tempos do circuito pulsional, inscritos discursivamente nas diversas modalidades de laço social, inscrevem em suas fórmulas igualmente o

R. Inter. Interdisc. INTERthesis, Florianópolis, v.12, n.2, p.55-73, Jul-Dez. 2015 
mal-estar que sua operação prescreve. É o objeto a, a parte excluída pela renúncia ao gozo, da linguagem, que cifra nas fórmulas dos discursos a parte perdida pela necessária renúncia pulsional.

Como indica Freud em 1930 no texto Mal-Estar na Civilização (ESB, v. XXI, p. 116), há uma tendência no sujeito a tomar o outro como um objeto a ser consumido, tanto sexual quanto agressivamente. Esta inclinação em querer abusar, explorar, torturar e matar seu semelhante, está ligada a pulsão de morte erotizada, que, segundo Quinet (2013), deve ser aparelhada discursivamente para possibilitar o laço social. Freud, no Projeto (1895), já mencionara algo que vai para a mesma direção ao trabalhar o desamparo (Hilflosigkeit), como veremos a seguir.

\section{A QUESTÃO DO DESAMPARO (HILFLOSIGKEIT) EM FREUD}

Os textos O Projeto (1895), Inibições, Sintomas e Angústia (1926), O Futuro de uma Ilusão (1927) e Mal-Estar Estar na Civilização (1930), são pilares para o estudo da noção de desamparo em Freud, além de outros textos de sua obra que enriquecem e problematizam ainda mais essa noção metapsicológica. É nele que encontramos a base da articulação entre a constituição do sujeito e o apelo originário ao outro, marca estrutural do sujeito freudiano.

$\mathrm{Na}$ primeira parte de O Projeto intitulada Esquema Geral, item 11, $A$ Experiência de Satisfação, o desamparo (Hilflosigkeit) aparece como um estado de impotência, de incapacidade do bebê em satisfazer suas necessidades vitais:

[...] O organismo humano é, a princípio, incapaz de promover essa ação específica. Ela se efetua por ajuda alheia, quando a atenção de uma pessoa experiente é voltada para um estado infantil por descarga através da via de alteração interna. Essa via de descarga adquire, assim, a importantíssima função secundária da comunicação, e o desamparo inicial dos seres humanos é a fonte primordial de todos os motivos morais (FREUD, ESB, v. I, p. 379).

Freud denomina de desamparo, nessa passagem do Projeto, o despreparo do organismo humano quando de seu nascimento. Essa incapacidade motora que gera a dependência ao outro para dar conta de suas necessidades vitais, implicará, do ponto de vista psíquico, numa série de vicissitudes na vida do sujeito. 
Ainda no texto O Projeto (1895), Freud considera o "desamparo inicial do bebê como protótipo de toda situação traumática. [...] O desamparo e a satisfação organizam os dois modos de funcionamento mental" (ESB, v. I, p. 379-381).

O desamparo expressa assim uma dimensão fundamental sobre a qual repousa a constituição subjetiva, e não apenas uma etapa do desenvolvimento infantil, uma regressão neurótica a essa dependência ou o núcleo de uma situação traumática. Tal como Freud indica no texto Mal-Estar na Civilização (1930), também a civilização foi erigida no intuito de diminuir o desamparo, seja aquele vivido diante das forças da natureza, da debilidade do corpo ou do perecimento da vida. No entanto, é também na própria civilização, na relação com seus semelhantes, que o desamparo volta a incidir; são essas relações, isto é, os laços sociais, que terminam por produzir o maior obstáculo à satisfação e à felicidade.

Assim, ao mesmo tempo em que a leitura de textos freudianos sugere que os laços sociais podem ser vistos como a busca de uma solução para o desamparo, visto que sua energia provém de um dos desejos mais prementes da humanidade "a necessidade de proteção através do amor" (FREUD, ESB, v. XXI, p. 39), há o reconhecimento deste paradoxo fundamental que indica nos laços sociais a fonte principal do mal-estar.

Como Freud demonstra, a vida em sociedade é pautada em regras que buscam a adequação do sujeito ${ }^{3}$ à cultura, o que é sempre fonte de mal-estar. Mesmo que necessárias para o convívio social, elas produzem sofrimento no sujeito.

Em termos freudianos, acreditava-se que o 'represamento pulsional' seria suficiente para assegurar a ordem social na cultura, o que foi ponderado por Freud no texto O Futuro de uma Ilusão (1927):

Pensar-se-ia ser possível um reordenamento das relações humanas que removeria as fontes de insatisfação para com a civilização pela renúncia à coerção e à repressão das pulsões, de sorte que, imperturbados pela discórdia interna, os homens pudessem dedicar-se à aquisição da riqueza e à sua fruição. [...] Parece, antes, que toda civilização tem de se erigir sobre a coerção e a renúncia à pulsão; [...] Acho que se tem que levar em conta o

\footnotetext{
${ }^{3}$ Apesar do termo sujeito ter sido elaborado conceitualmente por Lacan, em Freud encontramos base para seu uso. No texto As Pulsões e seus Destinos (1915) Freud utiliza o termo sujeito para designar a atividade pulsional originária do movimento reflexivo da pulsão, isto é, seu retorno à própria pessoa. Nessa visão, o sujeito da pulsão está submetido parcialmente à condição objetal, que produz ativamente uma passivação. Como afirma Poli (2005, p. 18) "o indivíduo-fonte da pulsão não é, necessariamente, e imediatamente sujeito: ele assume, igualmente, a condição de ser seu objeto, procurando uma Outra pessoa (Anderen person) que venha ocupar o lugar de sujeito".
}

R. Inter. Interdisc. INTERthesis, Florianópolis, v.12, n.2, p.55-73, Jul-Dez. 2015 
fato de estarem presentes em todos os homens tendências destrutivas e, portanto, antissociais e anticulturais, e que, num grande número de pessoas, essas tendências são suficientemente fortes para determinar 0 comportamento delas na sociedade humana (FREUD, ESB, v. XXI, p. 17).

Esta constatação o levou a concluir no texto de 1927 que "[...] o que chamamos de nossa civilização é em grande parte responsável pela nossa desgraça e que seríamos muito mais felizes se a abandonássemos e retornássemos às condições primitivas" (Ibid, p. 93). Após três anos, no texto Mal-Estar na Civilização (1930), Freud expõe as três fontes principais de sofrimento humano; entre elas, a principal é a relação entre seus pares. Esse mal-estar faz parte, está incluído - não há laço social sem o mal-estar - sempre que a relação com a alteridade estiver colocada.

Ao verificarmos a composição da palavra alemã Hilflosigkeit, segundo Michaelis (2009, p. 146-150-191), observamos que ela tem por núcleo Hilflos, adjetivo que significa "desamparado, sem ajuda, sem auxílio". Los é "ausência de algo", um sufixo que anula a ação do verbo Helfen (ajudar, socorrer). Keit é uma terminação que designa substantivo. Hilflosigkeit literalmente significa "ausência de ajuda". É o desamparo, em que não há ajuda, nem ninguém para proteger: falta a ação de ajuda. As duas palavras que compõem Hifflosigkeit pressupõe uma interação com o Outro ${ }^{2}$ que não acontece: trata-se da ausência do amparo do Outro.

Seria aquele bebê, evocado no texto do Projeto, que, ao nascer indefeso e imaturo, torna-se dependente do Outro ${ }^{4}$ para sobreviver, e que precisa de uma 'ação específica', da ajuda de um Outro, o modelo da felicidade? Claro que Freud está expressando, no texto de 1927, uma fantasia neurótica que produz essa ilusão pregressa de um estado de completude na infância como modo de recalcar o desamparo original, que é fundante e estruturante do psiquismo.

[...] Ele (o bebe) ainda não pensa, não fala, não tem nem mesmo a noção de ser um todo; é um pequeno organismo que percebe desconforto e dores, estado denominado por Freud de desamparo original (Hilflosigkeit). O único conforto que the advém é dado pela mãe ou por alguém que a substitua, que, entretanto, o bebê não percebe como mãe, pois não sabe identificar as totalidades. De todo modo, a mãe, único elo inicial entre o bebê e o mundo, é o primeiro Outro com o qual a criança tem contato (ALBERTI, 1999, p. 101-102).

${ }^{4} \mathrm{O}$ termo Outro se tornou um conceito na Psicanálise a partir de Lacan. Contudo, ele o retoma de Freud (ESB, v. I, p. 393) que, no Projeto (1895) faz uma referência a um outro: "suponhamos que o objeto que compõe a percepção se pareça com o sujeito - um outro (Anderen) ser humano. [...] é em relação a seus semelhantes que o ser humano aprende a se conhecer".

R. Inter. Interdisc. INTERthesis, Florianópolis, v.12, n.2, p.55-73, Jul-Dez. 2015 
Ao longo da obra freudiana, a ideia do desamparo (Hilflosigkeit) se amplia. Esse termo passa a designar também a condição de existência do sujeito na civilização, gerador de angústia. No texto Inibições, Sintomas e Angústia (1926) Freud retorna à concepção do Projeto (1895) e liga explicitamente o estado de desamparo à prematuração do ser humano:

\begin{abstract}
O fator biológico é o longo período de tempo durante o qual o jovem da espécie humana está em condições de desamparo e dependência. Sua existência intrauterina parece ser curta em comparação com a da maior parte dos animais, sendo lançado ao mundo num estado menos acabado. Como resultado, a influência do mundo externo real sobre ele é intensificada e uma diferenciação inicial entre o eu e o id é promovida. Além disso, os perigos do mundo externo têm maior importância para ele, de modo que o valor do objeto que pode somente protegê-lo contra eles e tomar o lugar da sua antiga vida intrauterina é enormemente aumentado. $\mathrm{O}$ fator biológico, então, estabelece as primeiras situações de perigo e cria a necessidade de ser amado que acompanhará a criança durante o resto de sua vida (FREUD, ESB, v. XX, p. 151).
\end{abstract}

Funcionando como uma abertura ao mundo adulto, ao mundo do Outro, o desamparo infantil possibilita ao bebe vivenciar uma primeira experiência de satisfação, proporcionada pela intervenção do Outro. Essa abertura é essencial, visto que possui o caráter inaugural do psiquismo que, em última instância, funda-se no desamparo.

Em consequência a esse primeiro estado psíquico aparece o da satisfação do desejo, em que os traços da primeira satisfação são investidos tornando a expectativa de um reencontro suportável. Essa dinâmica pulsional gera um novo tipo de necessidade, não mais fisiológica, mas psíquica: a demanda por amor, afeto, carinho, cujos destinos serão diversos e se expressam em diversas formas discursivas.

Neste sentido, podemos afirmar que o processo de desejo se instaura no encontro com o Outro e onde havia o desamparo e a impotência surge o desejo. Em O Projeto (1895), Freud esclarece que

Quando a pessoa que ajuda executa o trabalho da ação específica no mundo externo para o desamparado, este último fica em posição, por meio de dispositivos reflexos, de executar imediatamente no interior de seu corpo a atividade necessária para remover o estímulo endógeno. A totalidade do evento constitui então a experiência de satisfação, que tem as consequências mais radicais no desenvolvimento das funções do indivíduo (FREUD, ESB, v. I, p. 379).

R. Inter. Interdisc. INTERthesis, Florianópolis, v.12, n.2, p.55-73, Jul-Dez. 2015 
Observa-se assim que, ao longo de sua obra, Freud considera o desamparo como a base do funcionamento do psiquismo mais do que um tema restrito ao tempo originário. O desamparo motor torna-se desamparo psíquico e acompanha o sujeito ao longo de sua vida e está na base dos laços sociais.

Lacan, na Lição 24, de 10 de junho de 1959, no Seminário 6 (1958-1959), O Desejo e sua Interpretação, mostra que a Hilflosigkeit freudiana é uma posição primitiva, que remete à estar "sem recurso" diante do desejo do Outro:

\begin{abstract}
A Hilflosigkeit de Freud, [...] é esta posição de estar sem recurso, mais primitiva que todas, e em relação à qual a angústia é já um esboço da organização, pois ela já é esperada. [...] mas antes existe isto, Hilflosigkeit, o "sem recurso". O "sem recurso" diante de que? O que não pode ser definível, centrável de nenhum outro modo senão diante do desejo do Outro. É essa relação do desejo do sujeito, na medida em que ele deve se situar diante do desejo do Outro que, entretanto, literalmente o aspira e o deixa sem recursos, é nesse drama da relação do desejo do sujeito com o desejo do Outro que se constitui uma estrutura essencial, não somente da neurose, mas de qualquer outra estrutura analiticamente definida (LACAN, 2002, p. 452).
\end{abstract}

A produção discursiva, indicada por Lacan anos mais tarde, dispõe os lugares possíveis ao sujeito e o situa frente às adversidades, no campo do Outro. Podemos afirmar que as diferentes modalidades discursivas são formas de inscrever e circunscrever o desamparo, tornando-o operativo. Além disso, a teoria dos discursos nos indica que a psicanálise possibilita ao sujeito mudar sua posição frente ao Outro, reconhecer s

\title{
2. OS DISCURSOS COMO LAÇOS SOCIAIS NA VISÃO DE LACAN
}

O objetivo de Lacan ao elaborar o seminário 17, O Avesso da Psicanálise (1969-1970), foi o de propor uma nova forma de compreender como os laços sociais se estabelecem, inovando ao articular os campos da linguagem e do gozo. Através dessa articulação, Lacan propõe a prática analítica como uma experiência de discurso, que, como afirma o autor, cria laço.

Nesse seminário, Lacan se estende mais longamente sobre os discursos, situando-os como aparelhos de linguagem que estruturam o campo do gozo. Em 1968, época da elaboração da teoria dos quatro discursos, diversas revoltas estudantis abalaram Paris, que focavam justamente a burocratização da 
universidade, do qual advêm a fórmula do discurso universitário, que marca o momento histórico vivenciado por Lacan.

No texto Produção dos quatro discursos (1969), no seminário 17, Lacan (1992, p. 14) denomina os laços sociais de "aparelhos de gozo", pois promovem um esvaziamento, uma perda real de gozo no estabelecimento de regras de convívio em suas relações com o Outro. Através desses limites do gozo, efetuados pela linguagem, é que os laços sociais são compostos e estabelecem os vínculos e sua manutenção. Sem esse limite cultural, que é simbólico, a tendência do homem - tal como Freud já indicara - é tratar o outro como seu objeto de gozo e nele saciar suas pulsões erótica e de morte.

O outro facilmente se torna alvo das pulsões destrutivas e agressivas, principalmente se há a ameaça de revelar o desamparo psíquico que as ideologias disfarçam.

Todo laço social é uma representação, que não é da ordem do falso, é do semblante. O semblante não está por relação com o verdadeiro, e sim com o real e, conforme explicitado por Quinet (2013), é a aparência, forma, aspecto, que está na mesma raiz etimológica de "o semelhante". É um conceito que Lacan desenvolveu no Seminário 18, De um discurso que não fosse semblante (1971), que pressupõe que não há laço social que não seja semblante. O semblante é essencial para que o laço social funcione: a verdade está no semblante, que é sustentado por ela: [semblante/verdade] $\rightarrow$ [outro/produção].

O amor - assim como a psicose, onde falta o Nome-do-Pai, responsável pela estruturação do registro simbólico - não está no laço social. Correspondendo aos discursos, como laços sociais de Lacan, estão ao que Freud nomeou como as profissões impossíveis, como uma proposta de formalizar as modalidades de vínculo entre as pessoas: governar, equivale ao discurso do mestre - DM; educar, ao discurso universitário - DU; e psicanalisar, ao discurso do analista - DA.

Lacan (1992, p. 29-32) acrescentou mais dois discursos: o fazer desejar, que equivale ao discurso da histérica ou do histérico - $\mathrm{DH}$ e o fazer comprar, do discurso do capitalista - DC. Pertencer a uma cultura implica em estar inserido num desses discursos. Eles podem ser sem palavras, como diz preferir Lacan valorizando a condição de ato presente nos discursos. 
O gozo está presente em qualquer laço social e o discurso em seu campo é um discurso sem palavras, mas que vai para além das enumerações, sendo da ordem da linguagem, pois nossos atos são inscritos em enunciados primordiais, passíveis de serem detectados ou interpretados. Através destes enunciados primordiais, são determinados os laços sociais, assim como são instauradas as relações fundamentais e estáveis diante da linguagem no campo do gozo, que não necessitam de palavras, pois já estão inscritos em nossa conduta.

Os discursos como laços sociais são formas de tratamento do real do gozo pelo simbólico. É um tratamento civilizatório que delineia e regula as relações dos homens entre si que são feitas de libido e tecidas de linguagem. $O$ tratamento civilizatório que se subdivide em discurso do mestre e discurso universitário apresenta seus avessos, que são avessos interpretantes: o discurso da histérica e o discurso do analista. Os quatro discursos são sustentados pelo Nome-do-Pai (QUINET, 2009, p. 52).

Lacan (1992, p. 40), seguindo a ordem da teoria dos conjuntos - a permutação circular, propõe fórmulas (matemas) para se pensar esses laços (discursos), donde encontram-se quatro elementos de linguagem, que são os significantes: $\mathbf{S}^{\mathbf{1}}$ (poder), $\mathbf{S}^{2}$ (saber), $\$$ (sujeito), a (gozo) - e quatro lugares:

\section{$\uparrow$ [agente/verdade] $\rightarrow$ [outro/produção] $\downarrow$.}

Os laços sociais são constituídos por lugares que são pré-determinados: como agente e como Outro. Esta predeterminação é estabelecida e transmitida de geração em geração aos seus agentes e seus outros, condição para a manutenção dos laços em uma sociedade. Estruturalmente há um que comanda, que provoca o discurso, que agencia a possibilidade de um laço social e um outro, que obedece a uma hierarquização imposta pelo próprio laço social, onde há uma dissimetria, que é essencial para se entender a relação do agente com o outro.

O agente do discurso é o lugar da dominante, é o que caracteriza cada discurso, é o elemento que governa, determina, transforma e exerce influência sobre todos os outros elementos, que agem de acordo com a dominante daquele discurso específico em que estão inseridos. Para Lacan (1992, p. 179) "o agente não é aquele que faz, mas aquele a quem se faz agir".

[...] o significante-mestre, ao ser emitido na direção dos meios de gozo que são aquilo que se chama o saber, não só induz, mas determina a castração. [...] Todos os significantes se equivalem de algum modo, pois jogam apenas 
com a diferença de cada um com todos os outros, não sendo, cada um, os outros significantes. Mas é também por isso que cada um é capaz de vir em posição de significante-mestre, precisamente por sua função eventual ser a de representar um sujeito para todo outro significante. (LACAN, 1992, p. 93).

O sujeito circula por esses laços, pois ao se desdobrar a estrutura de cada um, eles se derivam. Na lógica dos discursos formulada por Lacan é fundamental estabelecer a diferença entre o lugar de ou a função de, pois o lugar que o sujeito ocupa é uma posição (mãe, pai, professor, aluno) em determinado discurso - ele está e não é, diferenciando-o do elemento (poder, saber, sujeito barrado e objeto a). Em todos os gráficos de Lacan, o que está do lado esquerdo é o sujeito, e do lado direto é o outro. Eis os matemas dos cinco discursos:

$$
\text { DM: } S^{1} / \$ \rightarrow S^{2} / a \quad \text { DH: } \$ / a \rightarrow S^{1} / S^{2} \quad \text { DU: } S^{2} / S^{1} \rightarrow a / \$
$$

$$
D A: a / S^{2} \rightarrow \$ / S^{1} \quad \text { DC: } \$ / S^{1} \rightarrow S^{2} / a
$$

$\mathrm{Na}$ composição dos discursos, a barra da primeira fração de cada um deles representa qual é a verdade em cada laço social e seu agente.

A barra da segunda fração dos matemas dos discursos diz respeito ao que o outro de cada laço social deve produzir. No discurso do mestre são os objetos de gozo para o mestre, para a sociedade, etc. No discurso universitário o que é produzido é o sujeito dividido (\$) que se revolta ou produz sintomas ao ser tratado como objeto a. No discurso da histérica é o saber $\left(\mathbf{S}^{2}\right)$ fabricado pelo mestre $\left(\mathbf{S}^{1}\right)$ e no discurso do analista, o analisante $(\$)$ produz o seu significante singular, como o sintoma analítico. O que caracteriza o discurso capitalista é a foraclusão da castração, ou seja, foraclusão da sexualidade e da diferença dos sexos. É um discurso que exclui o outro do laço social, visto que o sujeito se relaciona somente com os objetos - mercadorias comandadas pelo significante-mestre capital. Segundo Quinet (2009, p. 40) "é um discurso sem lei, que obedece à lógica da foraclusão, [...] é um discurso fora-do-discurso, onde não é possível o laço social, trata-se de discurso excluído".

Lacan define o sujeito (\$) no campo do gozo como o sujeito do inconsciente, irrepresentável, que embora esteja em relação à cadeia significante, não está dentro dela. É o significante pulado, barrado $(\$)$ da cadeia significante, que é produzido de 
forma retroativa pela insistência da repetição na cadeia de significantes $\left(\mathbf{S}^{1} / \mathbf{S}-\mathbf{S}^{2}\right)$, segundo Quinet (2009, p. 31)

Nesse contexto, o objeto a não é necessariamente o objeto causa do desejo, mas é definido no campo do gozo como mais-de-gozar (Mehrlust), visto que na repetição, à procura da experiência do $\mathbf{S}^{1}$, há um gozo de busca e também um gasto que tem como resultado o gozo fracassado, o que se chama entropia (gasto de energia). "A entropia da energia que cai dessa repetição que é o objeto a" (Quinet, 2009, p. 32), que nomeia o gozo não alcançado, fracassado, perdido, mas também é o gozo produzido na repetição significante. No discurso do mestre é o objeto precioso: o aluno no discurso universitário; no discurso da histérica, o objeto é que sustenta a provocação dirigida ao médico e no discurso capitalista ele é a mercadoria (gadget). No discurso do analista (DA) é o objeto que causa o desejo: o analista não está como sujeito e sim como objeto.

A questão é articular o que há dessa exclusão fálica no grande jogo humano de nossa tradição, que é o desejo. $O$ desejo não tem relação próxima com esse campo. Nossa tradição o apresenta como o que ele é, Eros, a presentificação da falta (LACAN, 1992, p. 80).

A proposta de Lacan ao indicar o discurso como um modo de relacionamento social, representado por uma estrutura sem palavras, demonstra que é na estrutura do significante que o discurso se funda. Nesse enfoque, os quatro discursos são quatro significantes que regulam e ordenam os laços sociais entre os sujeitos. $\mathrm{O}$ sujeito que emerge dessa relação significante é o sujeito do inconsciente, clivado, vazio, que se caracteriza pela constante necessidade de vir a ser, que interessa à Psicanálise.

\section{CONSIDERAÇÕES FINAIS}

A história nos mostra que o sujeito sempre recorreu a elementos internos ou externos para lidar com seu desamparo, que é, como visto, constitucional. No texto Reflexões para os tempos de guerra e morte (1915), Freud esclarece que

[...] o fator interno consiste na influência exercida sobre as pulsões más (digamos, egoístas) pelo erotismo - isto é, pela necessidade humana de amor, tomada em seu sentido mais amplo. Pela mistura dos componentes eróticos, as pulsões egoístas são transformadas em sociais. [...] O fator externo é a força exercida pela educação, que representa as reivindicações de nosso ambiente cultural, posteriormente continuadas pela pressão direta desse ambiente. A civilização foi alcançada através da renúncia à satisfação pulsional, exigindo ela, por sua vez, a mesma renúncia de cada recém-

R. Inter. Interdisc. INTERthesis, Florianópolis, v.12, n.2, p.55-73, Jul-Dez. 2015 
chegado. No decorrer da vida de um indivíduo, há uma substituição constante da compulsão externa pela interna (FREUD, ESB, v. XIV, p. 291292).

O desamparo (Hilflosigkeit) se singulariza na história de cada sujeito, a partir da relação de dependência com aquele ou aquela que cuida, que se tornará responsável em Ihe transmitir a vida psíquica caracterizada pela impossibilidade do neném em lidar com as exigências pulsionais, sobretudo pela inexistência de um aparelho psíquico ao nascer. As ligações pulsionais produzem investimentos libidinais que confortam, de forma imaginária, o frágil ego em constituição.

Como elemento causal da linguagem no campo do gozo, o objeto a representa a presença da libido nos discursos. O objeto a é o supereu no campo do gozo, responsável, segundo Freud (ESB, v. XXI, p. 93) pelo mal-estar na civilização.

$\mathrm{Na}$ tentativa de elaborar algum sentido para a falta, advém a angústia, e dá margem ao surgimento do desamparo. A pulsão (força) versus o sentido (significado, representação) são dois pilares fundamentais para a compreensão do ser humano, principalmente para o analista, responsável em desvendar os mistérios da mente de pacientes, segundo Comaru (2012).

$\mathrm{Na}$ angústia, o sujeito é afetado pelo desejo do Outro, de maneira imediata. Ela não é seu objeto. O objeto a é o que caiu, do sujeito, na angústia. É o objeto causa do desejo. O pequeno a na fantasia é o suporte do desejo. Em sua realização de sujeito, o desejo "é o mais intensivo do que é dado ao sujeito atingir no nível da consciência" (LACAN, 2005, p. 59). Por essa cadeia é que se afirmam as dependências do desejo em relação ao desejo do Outro.

Lacan (2010, p. 445), no texto A Angústia na sua Relação com o Desejo, no Seminário 8 , sobre $A$ Transferência, faz referência ao desamparo que dá origem à irrupção da angústia em sua relação com o desejo:

No Hilflosigkeit, o desamparo, o sujeito é pura e simplesmente transtornado, ultrapassado por uma situação eruptiva que não pode enfrentar de modo algum. Entre isso e empreender a fuga [...] existe uma outra solução, e é o que Freud nos indica sublinhando na angustia seu caráter de Erwartung (expectativa). Aí está a característica central. O fato de que possamos fazer dela, secundariamente, a razão de fugir é uma coisa, mas não é este o seu caráter essencial. Seu caráter essencial é o Erwartung, e é isso o que designo a vocês ao dizer-lhes que a angustia é modo radical sob o qual é mantida a relação com o desejo. Quando, por razões de resistência, de defesa e de outros mecanismos de anulação do objeto, o objeto desaparece, permanece o que dele pode restar, a saber, o Erwartung, a direção para o seu lugar, lugar de onde ele, a partir de então, se ausenta, onde passa a tratar-se apenas de um unbestimmte Objekt (objeto

R. Inter. Interdisc. INTERthesis, Florianópolis, v.12, n.2, p.55-73, Jul-Dez. 2015 
indeterminado), ou ainda, como diz Freud, de um objeto com que estamos numa relação de Löslichkeit (envolvimento). Quando atingimos este ponto, a angústia é o ultimo modo, modo radical, sob o qual o sujeito continua a sustentar, mesmo que de uma maneira insustentável, a relação com o desejo (LACAN, 2010, p. 445).

Nota-se que no texto de 1915, Reflexões para os tempos de guerra e morte, a guerra trouxe para as reflexões freudianas o tema da violência humana e no texto Psicologia de Grupo e Análise do Eu, de 1921, Freud retomou a relação entre laço social e ilusão, mas com um novo enfoque, com a inclusão do conceito de Narcisismo na análise do social, segundo Mograbi (2009, p. 34). O sujeito para a Psicanálise só pode ser concebido a partir de sua relação com os Outros.

No modelo de subjetivação atual há o investimento pela cultura do narcisismo, que valoriza a exterioridade. O destino dos desejos assume, também, uma direção exibicionista e autocentrada, "[...] na qual o horizonte intersubjetivo se encontra esvaziado e desinvestido das trocas inter-humanas. Esse é o trágico cenário para a implosão e a explosão da violência que marcam a atualidade", segundo Birman (2009, p. 24).

No Seminário 1, Os Escritos Técnicos de Freud, Lacan sustenta que Freud, no texto de 1914 sobre O Narcisismo: uma introdução, designa duas funções diferenciadas ao tratar do ideal do eu e do eu ideal, e que estas estão intimamente ligada às relações sociais do sujeito:

O que é ligação amorosa? [...] socialmente nós nos definimos por intermédio da lei. É da troca dos símbolos que nós situamos uns em relação aos outros nossos diferentes eus - você é você, e eu, Jacques Lacan, e estamos numa certa relação simbólica, que é complexa, segundo os diferentes planos em que nos colocamos. [...] Em outros termos, é a relação simbólica que define a posição do sujeito como aquele que vê. É a palavra, a função simbólica que define o maior ou menor grau de perfeição, de completude, de aproximação, do imaginário. A distinção é feita nessa representação entre o Ideal-Ich e o Ich-Ideal, entre o eu ideal e o ideal do eu. $O$ ideal do eu comanda o jogo de relações de que depende toda a relação a outrem. E dessa relação a outrem depende o caráter mais ou menos satisfatório da estruturação imaginária (LACAN, 1996, p. 165).

Assim, a cultura do narcisismo impossibilita a admiração pelo Outro em sua diferença, visto que o sujeito se foca em si mesmo, encarando o Outro como objeto para seu usufruto. O poder de Eros não é suficientemente forte para manter as ligações de objeto que garantem o processo civilizatório. Este não torna o sujeito mais feliz, pois há a resistência da função sexual e do narcisismo. Observa-se que o progresso científico não trouxe nenhum aumento de nível de satisfação e de prazer.

R. Inter. Interdisc. INTERthesis, Florianópolis, v.12, n.2, p.55-73, Jul-Dez. 2015 
Os laços sociais não são imunes a estas vicissitudes. As ligações de Eros são facilmente rompidas por uma ameaça narcísica de perda do objeto de satisfação, como demonstram as guerras. Levando-se em conta que na solução de satisfação impera o narcisismo, os laços sociais servem para manter as ilusões.

Para Birman (2009, p. 36-37), os homens, como seres finitos, frágeis e mortais, necessitam criar artifícios para preencher as marcas da suposta auto suficiência e da onipotência. Essa formulação já havia sido enunciada no texto freudiano MalEstar na Civilização (1930), fundamentando o que Freud já havia postulado na segunda teoria das pulsões, na qual se baseia não somente sobre o desamparo do sujeito, mas também na presença da pulsão de morte no psiquismo humano, como colocado no texto Além do Princípio do Prazer (1920).

Ao admitir a existência de uma modalidade de pulsão sem representação e que não se inscreve na satisfação de um objeto, Freud fornece a base para se pensar na posição do sujeito na condição de desamparo, que é insuperável, é da ordem originária, que marca a subjetividade humana de forma perpétua. O sujeito é desamparado por natureza e não por acidente histórico-evolutivo.

Por isso Freud enuncia claramente que a felicidade jamais pode ser alcançada, somente de forma singular, possibilitada pela economia pulsional. Este seria um dos motivos da existência do mal-estar em que Freud critica a tradição do Ocidente com o discurso iluminista da ciência, no final do século XVIII, que prometeu bem-estar para todos.

Através desse conjunto de transformações conceituais e valores que direcionavam a Psicanálise, o discurso freudiano passou a colocar, no fundamento do sujeito, o desamparo, que assume agora um perfil trágico, marcado pela finitude e imprevisível.

Diante do desamparo primordial, o sujeito se encontra frente à pressão constante das forças pulsionais que 0 atravessam e 0 inundam em diferentes direções. O sujeito é invadido pelo excesso, cabendo a ele erguer circuitos pulsionais que ajudem a dominar as intensidades que o afetam assim como criar representações simbólicas para desviar esses excessos pulsionais, de forma constante e renovada, visto que a força da pulsão é regular e repetitiva. 
O mal-estar da nossa civilização é produto dos discursos dominantes em nossa era: do mestre, do universitário e do capitalismo. Visto como discursos do avesso da civilização levam em consideração a pulsão (objeto a): como verdade no discurso histérico e no lugar de agente, no discurso do analista.

Nossa biografia determina a nossa forma de amar e de nos defender. Podemos dizer que o Édipo é uma dramatização no plano individual da problemática transindividual do desamparo - é como o sujeito vivencia o desamparo dentro de casa. No final de Édipo o desamparo encontra a castração, que é falta que nos move, que nos impulsiona ao encontro do desejo. 


\title{
THE SOCIAL TIE AND THE MALAISE FACING THE HELPLESSNESS
}

\begin{abstract}
:
In this article we intend to approach the discourses as social ties, indicated by Lacan, relating them to the freudian concepts of helplessness (Hilflosigkeit) and the malaise of civilization. The theory of discourses opens up a new way of thinking about clinical structures and social ties, by articulating language and enjoyment camps, the subject and the unconscious knowledge. This theory, while it takes over Freudian principles, it advances in impasses left by the Viennese master, in particular on the relationship between the metapsychological foundations of the subjective constitution and the conceptual bases concerning culture and actual social ties.
\end{abstract}

Keywords: Psychoanalysis. Social ties. Helplessness. Discourses. Malaise

\section{EL VÍNCULO SOCIAL Y EL MALESTAR ANTE DEL DESAMPARO}

\section{Resumen:}

En este artículo nos proponemos abordar los discursos como vínculos sociales, como lo indica Lacan, relacionándolos con las concepcions freudianas de desamparo (Hilflosigkeit) y malestar de la civilización. La teoría del discursos abre una nueva forma de pensar acerca de las estructuras clínicas y los vínculos sociales, por articular los campos del lenguaje y del gozo, el sujeto y el saber inconsciente. Esa teoría, al mismo tiempo que retoma principios freudianos, avanza en impasses dejados por el maestro vienés, en particular en la articulación entre los fundamentos metapsicológicos de la constitución subjetiva y las bases conceptuales concernientes a la cultura y a los vínculos sociales propiamente dichos.

Palabras clave: Psicoanálisis. Vínculos sociales. Desamparo. Discursos. Malestar. 


\section{REFERÊNCIAS}

ALBERTI, Sonia. Esse sujeito adolescente. Rio de Janeiro: Rios Ambiciosos, 1999.

BIRMAN, Joel. Mal-estar na atualidade: a psicanálise e as novas formas de subjetivação. 7.ed. Rio de Janeiro: Civilização Brasileira, 2009.

COMARU, Marcos. A expressão contemporânea do desamparo. Curso de curta duração. Polo de Pensamento Contemporâneo - POP, Rio de Janeiro, 2012.

FREUD, Sigmund. (1895). Projeto para uma psicologia científica. In Publicações pré-psicanalíticas e esboços inéditos (1886-1889). Tradução Jayme Salomão. Rio de Janeiro: Imago, 1996. (ESB, v. I).

FREUD, Sigmund (1915). As pulsões e seus destinos. In A história do movimento psicanalítico, artigos sobre a metapsicologia e outros trabalhos (1914-1916). Tradução Jayme Salomão. Rio de Janeiro: Imago, 2006 (ESB, v. XIV).

FREUD, Sigmund (1915). Reflexões para os tempos de guerra e morte. In op. cit.

FREUD, Sigmund (1920). Além do princípio do prazer. In Além do princípio do prazer, psicologia de grupo e outros trabalhos (1920-1922). Tradução Jayme Salomão. Rio de Janeiro: Imago, 2006 (ESB, v. XVIII).

FREUD, Sigmund (1921). Psicologia de grupo e análise do eu. In op. cit.

FREUD, Sigmund (1926). Inibições, sintomas e ansiedade. In Um estudo autobiográfico, inibições, sintomas e ansiedade, análise leiga e outros trabalhos (1925-1926). Tradução Jayme Salomão. Rio de Janeiro: Imago, 2006 (ESB, v. XX).

FREUD, Sigmund (1927). O futuro de uma llusão. In O futuro de uma ilusão, o malestar na civilização e outros trabalhos (1927-1931). Tradução Jayme Salomão. Rio de Janeiro: Imago, 2006. (ESB, v. XXI). 
FREUD, Sigmund (1930). O mal-estar na civilização. In op. cit.

LACAN, Jacques. Escritos. Tradução Vera Ribeiro. Rio de Janeiro: Zahar, 1998.

LACAN, Jacques. Nomes-do-pai. Tradução André Telles. Rio de Janeiro: Jorge Zahar, 2005.

LACAN, Jacques. O Seminário, livro 1. Os escritos técnicos de Freud (19531954). Texto estabelecido por Jacques-Alain Miller. Tradução Betty Miler. Rio de Janeiro: Zahar, 1996.

LACAN, Jacques. O Seminário, livro 6. O Desejo e sua Interpretação (19581959). Versão produzida por membros e colaboradores da Associação Psicanalítica de Porto Alegre: 2002. Inédito.

LACAN, Jacques. O Seminário, livro 8. A Transferência (1960-1961). 2.ed.Texto estabelecido por Jacques-Alain Miller. Tradução Dulce Duque Estrada. Rio de Janeiro: Zahar, 2010.

LACAN, Jacques. O Seminário, livro 17. O avesso da psicanálise (1969-1970). Texto estabelecido por Jacques-Alain Miller. Consultor Antônio Quinet. Rio de Janeiro: Zahar, 1992.

LACAN, Jacques. O Seminário, livro 18. De um discurso que não fosse semblante (1971). Texto estabelecido por Jacques-Alain Miller. Tradução Vera Ribeiro. Rio de Janeiro: Zahar, 2009.

MICHAELIS. Dicionário alemão-português, português-alemão. 2. ed. Alfred J. Keller. São Paulo: Melhoramentos, 2009.

MOGRABI, Daniel. O laço social na teoria freudiana: para além da nostalgia e da esperança. Curitiba: Juruá, 2009. 
POLI, Maria Cristina. Clínica da Exclusão: a construção do fantasma e o sujeito adolescente. São Paulo: Casa do Psicólogo, 2005.

QUINET, Antônio. Psicanálise e laços sociais. Disciplina do Doutorado em Psicanálise, Saúde e Sociedade. Rio de Janeiro: Universidade Veiga de Almeida, 2013.

QUINET, Antônio. Psicose e laço social: esquizofrenia, paranoia e melancolia. 2.ed. Rio de Janeiro: Jorge Zahar, 2009.

\section{Artigo:}

Recebido em 20 de Maio de 2015

Aceito em 08 de Dezembro de 2015 